\title{
DETECÇÃO DE LIMITES DE SOLOS POR DADOS ESPECTRAIS E DE RELEVO ${ }^{(1)}$
}

\author{
José A.M. Demattê ${ }^{(2)}$, Marcelo R. Alves ${ }^{(3)}$, Bruna Cristina Gallo ${ }^{(4)}$ \& Caio T. Fongaro ${ }^{(5)}$
}

\section{RESUMO}

\begin{abstract}
Existe a necessidade de avaliar a importância do relevo associado aos parâmetros espectrais de solos como base no mapeamento. $O$ objetivo deste trabalho foi determinar um método de deteç̧ão de limites de solos por meio da interação de dados espectrais e formas de relevo. Foram percorridas 14 topossequências representativas de uma área de 13.000 ha próxima dos municípios de São Carlos e Araraquara, SP. As amostras foram caracterizadas pelos métodos convencionais de análise química e granulométrica. Posteriormente, foram obtidos dados espectrais de 400 a $2.500 \mathrm{~nm}$. As informações do relevo foram obtidas pelo emprego de técnicas de geoprocessamento. Geraram-se o modelo digital de elevação do terreno e os mapas de declividade, de curvatura, de índice topográfico composto e de Potencial de Densidade de Drenagem. Ainda, procedeu-se à validação dos métodos pontual e espacial. Na primeira validação, os pontos classificados nas topossequências foram tomados como verdadeiros e contrastados com as informações contidas no mapa de solo pré-existente, com os dados de relevo e com os dados espectrais agrupados. $\mathrm{Na}$ validação em nível espacial, procuraram-se avaliar em que locais os diferentes métodos indicavam mudanças nos limites dos solos e comparar com as observações reais. Verificou-se que a análise de agrupamento com cluster evidenciou-se eficiente na discriminação das unidades de solos em topossequência, quando utilizados parâmetros espectrais do solo. Já o conjunto de parâmetros de relevo isoladamente não foi o mais adequado.
\end{abstract}

Termos de indexação: topossequência, reflectância, análise de cluster.

(1) Recebido para publicação em 9 de julho de 2013 e aprovado em 15 de janeiro de 2014.

(2) Professor, Departamento de Ciência do Solo, Escola Superior de Agricultura "Luiz de Queiroz", Universidade de São Paulo ESALQ/USP. Av. Pádua Dias, 11. Caixa Postal 9. CEP 13418-900 Piracicaba (SP). E-mail: jamdemat@usp.br

(3) Dr. Solos e Nutrição de Plantas ESALQ/USP, Consultor da CSolos Mapeamento \& Consultoria. E-mail: marcelo@csolos.com.br

(4) Mestranda em Solos e Nutrição de Plantas, Departamento de Ciência do Solo, ESALQ/USP. E-mail: gallo.bruna@gmail.com

(5) Mestrando em Solos e Nutrição de Plantas, Departamento de Ciência do Solo, ESALQ/USP. E-mail: caio.fongaro@gmail.com 


\title{
SUMMARY: DETECTION OF SOIL CLASS BOUNDARIES BASED ON SPECTRAL AND RELIEF DATA
}

\begin{abstract}
There is a need to evaluate the importance of soil relief together with soil spectral attributes as the basis on soil mapping. The aim of this study was to test a method for detecting soil boundaries through the interaction of spectral data and relief features. Fourteen toposequences were used, representing an area of 13,000 ha near the municipalities of São Carlos and Araraquara, SP, Brazil. The samples were described by the conventional method of chemical and particle size analysis, such as $\mathrm{pH}\left(\mathrm{H}_{2} \mathrm{O}\right.$ and $\left.\mathrm{KCl}\right)$, size (coarse and fine sand, silt, and clay), iron content, and color. Spectral information from 400 to 2,500 $\mathrm{nm}$ was subsequently obtained. Relief information was obtained by geotechnics, such as the Digital Elevation Model of the terrain, slope map, Compound Topographic Index, curvature, and Drainage Density Potential. In addition, the point and spatial methods proposed were validated. In the first validation, the points classified in the toposequences were taken as true and compared to information contained in the existing soil map, as well as the relief data and spectral data, separated by cluster analysis. Validation on the spatial level sought to assess in which locations the different methods indicated changes in the soil boundaries and compare this with real observations. It was seen that cluster analysis proved to be effective in differentiating soil classes in toposequences when soil spectral attributes were used. However, the set of relief attributes alone was not very suitable.
\end{abstract}

Index terms: toposequence, reflectance, cluster analysis.

\section{INTRODUÇÃO}

Nos últimos anos, a temática do mapeamento tem passado por grandes mudanças em razão dos adventos da informática. Isso tem proporcionado o uso de geotecnologias, como Sistemas de Informações Geográficas (SIG) e produtos de Sensoriamento Remoto.

Uma das ferramentas geotecnológicas mais difundidas e utilizadas na determinação de aspectos da paisagem são os Modelos Digitais de Elevação (MDE). Os MDE constituíram-se numa importante ferramenta de aplicação dos SIG, que por meio desses atributos do relevo são derivados e utilizados na caracterização da paisagem (Dobos et al., 2000; Ziadat, 2005). Diferentes modelos estatísticos têm sido empregados para estabelecer relações quantitativas entre formas da paisagem derivadas de MDE e da distribuição de propriedades do solo (Gessler et al., 1995; McKenzie et al., 2000). Essa abordagem é útil nos levantamentos de solos por explicar as relações entre as formas da paisagem e das propriedades do solo; propiciar rapidez e facilitar ajustes em mapas de solos; proporcionar melhor representação das mudanças graduais e contínuas das propriedades dos solos; disponibilizar produtos de informações digitais; reduzir custos (Zhu et al., 2001).

Vários são os trabalhos que têm verificado a relação entre unidades de solo e formas de relevo. Goodman (1999) demonstrou que o perfil do solo foi significantemente correlacionado com o ângulo de declividade do terreno. Já Gessler et al. (1995) encontraram correlação entre o horizonte A e a presença ou ausência do horizonte E com o plano de curvatura - índice de composição topográfica (CTI) - e a declividade média do plano de curvatura. Modelos que utilizam apenas o CTI puderam explicar 84 e $7 \%$ das variações nos perfis do solo e no horizonte A, respectivamente. Girgin \& Frazier (1996) constataram que a distribuição espacial do horizonte E pode ser estimada usando as variáveis de curvatura do terreno, a declividade e oaspecto. Moore etal. (1993) demonstraram que a declividade e o CTI explicaram $50 \%$ da variabilidade na camada do horizonte $\mathrm{A}$, do teor de areia e de outras propriedades do solo. Pachepsky et al. (2001) demonstraram que a declividade, a tangente e o perfil das curvaturas são os melhores fatores para estimativa da textura do solo e explicam mais de $60 \%$ das variações no conteúdo de água no solo.

A espectrorradiometria é também uma ferramenta advinda do desenvolvimento tecnológico e de grande uso na caracterização dos solos. O grande impulso na sua disseminação deu-se quando as imagens orbitais tornaram-se acessíveis, pois elas trouxeram consigo mais um importante elemento no estudo em questão: a visão sinótica e multiespectral. Com o advento dos sensores remotos e por eles permitirem medições em campo e, ou, em laboratório, desde a década de 1970 surgiu uma importante linha de pesquisa para caracterização dos solos pela sua energia refletida. A reflectância espectral permite estimar e classificar algumas características físicas e químicas dos solos em análises de laboratório.

A análise espectrorradiométrica em nível de laboratório conduz a resultados mais acurados e rápidos (Viscarra-Rossel et al., 2006a,b). As informações espectrais têm sido amplamente usadas em razão de o desenvolvimento do imageamento espectrorradiométrico abranger, inclusive, algumas propriedades do solo, óxidos de $\mathrm{Al}$, óxidos de $\mathrm{Fe}$, minerais de argila ou matéria orgânica e salinidade do solo (Ben-Dor et al., 2002). Expandir essas abordagens para todas as propriedades do solo que já 
foram determinadas em laboratório significa contribuir diretamente para melhorar o ajuste das equações empregadas no mapeamento digital dos solos, método aplicado na produção de mapas que recobrem grandes áreas e objeto de estudo deste trabalho.

Embora existam várias pesquisas comprovando a potencialidade da utilização dos atributos da paisagem como técnicas auxiliares em levantamentos de solos (Moore et al., 1993; Zhu \& Jossman, 1999; Zhu et al., 2001), esses trabalhos estão voltados, em sua maioria, para quantificação de atributos do solo e correlação com a unidade de mapeamento em si. Observou-se a deficiência de trabalhos que indiquem onde está havendo alteração relevante do relevo e por consequência apontem mudanças nas unidades de mapeamento. De forma sistemática, os dados espectrais vêm sendo estudados pontualmente, deixando uma lacuna no que se refere à detecção de limites de classes de solo e principalmente sua combinação com informações do relevo.

O objetivo deste trabalho foi determinar um método na detecção de limites de solos por meio da interação entre dados espectrais e formas de relevo. Sabe-se que alterações no relevo são indicativas de diferentes classes de solos. Da mesma forma, está comprovado que muitas características dos solos podem ser determinadas pela sua energia eletromagnética refletida. Espera-se que a junção dessas duas informações permita detectar limites de solos com maior precisão. A proposta visa reduzir a subjetividade da determinação desses limites.

\section{MATERIAL E MÉTODOS}

A área de estudo localiza-se na região nordeste do Estado de São Paulo, envolvendo municípios como São Carlos, Araraquara, entre outros. As altitudes na região variam de 450 a $800 \mathrm{~m}$ e o clima é do tipo Cwb, segundo a classificação climatológica de Köppen. A precipitação pluvial e temperatura média anual são de 1.000 a $1.800 \mathrm{~mm}$ e $20^{\circ} \mathrm{C}$, respectivamente.

A pesquisa teve seu ponto de partida no mapa de solos semidetalhado da área de estudo (Sousa Junior et al., 2008). Os solos foram classificados segundo o Sistema Brasileiro de Classificação de Solos - SiBCS (Embrapa, 2006). As principais classes de solos que ocorrem na região são os Latossolo Vermelho (LV), Latossolo Vermelho-Amarelo (LVA), Nitossolos Vermelho (NV), Argissolos Vermelho (PV) e Neossolos Quartzarênicos (RQ).

Os índices topográficos, descritos posteriormente, foram correlacionados com as unidades de solos do mapa semidetalhado pré-existente, o qual foi simplificado para que se trabalhasse apenas com as unidades de mapeamento classificadas até o terceiro nível categórico. Nos casos classificados como associações, foi considerada a classe predominante.
Em trabalho de escritório, foram selecionadas 14 topossequências representativas da área de estudo (Quadro 1), as quais se baseiam em informações de relevo (curvas planialtimétricas, modelo digital de elevação, rede de drenagem), informações espaciais (imagem de satélite Landsat TM 5) e informações de solo. Posteriormente, as topossequências foram traçadas em formato vetor (linha) com auxílio do software ArcGis 9.2 (ESRI, 2006). Ainda em ambiente SIG, foram marcados pontos com equidistância de $200 \mathrm{~m}$ ao longo das topossequências. Tais pontos foram convertidos para o formato raster e inseridos no aparelho GPS, para verificação de sua correta localização em campo. Todas as topossequências foram percorridas ponto a ponto para coleta de amostras de solo em duas profundidades (0-20 e 80-100 cm), num total de 124 pontos de amostragem.

Em laboratório, foram realizadas análises químicas e granulométricas (Camargo et al., 1987). Determinou-se também o teor de $\mathrm{Fe}_{2} \mathrm{O}_{3}$ total pelo método do ataque sulfúrico (Camargo et al., 1986). A cor das amostras foi obtida com as amostras úmidas por meio do colorímetro Minolta CR 300 para cor de Munsell (Campos et al., 2003).

A partir dos resultados das análises químicas e granulométricas, em conjunção com as observações de campo (perfis representativos), estabeleceu-se uma classificação pontual para os solos, ao longo das topossequências, obedecendo aos critérios capitulados pelo Sistema Brasileiro de Classificação dos Solos (SiBCS). Ressaltou-se que se adotou os agrupamentos texturais estabelecidos pelo SiBCS, com a exceção de que o grupo textura média (teor de argila entre $150 \mathrm{e}$ $350 \mathrm{~g} \mathrm{~kg}^{-1}$ ) foi subdividido para fins de detalhamento

Quadro 1. Distribuição das classes de solos dentro da área de estudo

\begin{tabular}{lrc}
\hline \multicolumn{1}{c}{ Unidade de mapeamento $^{(1)}$} & \multicolumn{2}{c}{ Área } \\
\hline & \multicolumn{1}{c}{ ha } & \multicolumn{1}{c}{$\%$} \\
Cambissolos Háplicos (CX) & 399 & 2,4 \\
Gleissolos Háplicos (GX) & 47 & 0,3 \\
Latossolos Amarelos (LA) & 3019 & 18,4 \\
Latossolos Vermelhos (LV) & 2844 & 17,3 \\
Latossolos Vermelho-Amarelos (LVA) & 1828 & 11,1 \\
Nitossolos Vermelhos (NV) & 776 & 4,7 \\
Nitossolos Vermelhos latossólicos (NVl) & 793 & 4,8 \\
Argissolos Amarelos (PA) & 209 & 1,3 \\
Argissolos Amarelos latossólicos (PAl) & 352 & 2,1 \\
Argissolos Vermelhos (PV) & 803 & 4,9 \\
Argissolos Vermelho-Amarelos (PVA) & 772 & 4,7 \\
Argissolos Vermelho-Amarelos latossólicos (PVAl) & 309 & 1,9 \\
Argissolos Vermelhos latossólicos (PVl) & 784 & 4,8 \\
Neossolos Litólicos (RL), & 59 & 0,4 \\
Neossolos Quartzarênicos (RQ) & 3351 & 20,4 \\
Planossolos Háplicos (SX) & 87 & 0,5 \\
\hline
\end{tabular}

(1) Nomenclatura de acordo com Embrapa (2006). 
do estudo em média argilosa (250 e $350 \mathrm{~g} \mathrm{~kg}^{-1}$ argila) e média (150 e $250 \mathrm{~g} \mathrm{~kg}^{-1}$ argila).

Utilizando-se de curvas de nível com equidistância vertical de $20 \mathrm{~m}$, foi gerado um modelo digital de elevação (MDE) com células de $20 \times 20 \mathrm{~m}$. O MDE representa, de forma contínua, os valores de elevação do terreno por meio de uma malha regular de coordenadas x, y e dos valores de z (elevação). Para processamento do modelo, utilizou-se o software ArcGis, com aplicação da função Topo to raster, com base no programa ANUDEM desenvolvido por Hutchinson (1993). A partir do MDE, geraram-se os mapas de declividade e curvatura. Os valores das células associam-se à concavidade ou convexidade das vertentes e relacionam-se a fatores como o teor de água no solo, o fluxo convergente/divergente e a taxa de erosão/deposição (Moore et al., 1991). As vertentes côncavas são representadas por células de valores negativos; as convexas, por positivos; e as planas, iguais a zero.

A partir do MDE, foram gerados o índice Topográfico Composto (CTI) e o Potencial de Densidade de Drenagem (PDD). O CTI é um fator de caráter hidrológico e estima a distribuição espacial de propriedades do solo (Moore et al., 1991; 1993). Comumente chamado de índice de umidade, caracteriza a distribuição espacial de zonas de saturação da superfície e o conteúdo de água dos solos na paisagem. Para o seu cálculo, utilizou-se o método proposto por Moore et al. (1993). Denota-se por PDD a função que deriva uma rede de drenagem a partir de um MDE e mede a densidade da rede de drenagem dentro de uma área predefinida (Dobos et al., 2000).

A partir dos pontos das tradagens ainda coletadas de forma automática em ambiente computacional, informações pontuais de cada índice topográfico foram produzidas. De posse dos dados topográficos pontuais, realizou-se correlação de Pearson com os resultados das análises granulométricas da camada subsuperficial (80-100 cm) de cada ponto de amostragem.

Em relação as topossequências, traçaram-se perfis longitudinais que foram confeccionados para todos os atributos topográficos produzidos. Esses foram sobrepostos ao mapa semidetalhado de solos, para que se destacassem mudanças de unidades de mapeamento. Acrescentaram-se também os novos limites das classes de solos que porventura foram encontrados na checagem de campo. Assim, foi possível analisar como cada topossequência comportou-se frente aos índices topográficos e observar se houve relação entre as quebras no relevo (mudanças bruscas de cada índice estudado) e as mudanças nas unidades de solo.

O sensor empregado foi o FieldSpec Spectroradiometer, cuja resolução espectral é de $1 \mathrm{~nm}$ nos comprimentos de onda de 350 a $1.100 \mathrm{~nm}$ e de $2 \mathrm{~nm}$ nos comprimentos que vão de 1.100 a $2.500 \mathrm{~nm}$. A geometria de aquisição seguiu procedimentos de Nanni
\& Demattê (2006), em que foi utilizada uma lâmpada halógena de $650 \mathrm{w}$, localizada a $35 \mathrm{~cm}$ da amostra de solo. A amostra ficou posicionada a $10 \mathrm{~cm}$ da fibra ótica do sensor. Utilizou-se uma placa branca como padrão. As curvas espectrais correspondentes a cada amostra de solo foram processadas no software AutoSignal v1.7 para suavização. O método aplicado foi o de Savitzky-Golay (1964), o qual usou um filtro ou tratamento dos dados digitais que suavizam os ruídos sem distorcer os dados, aplicado em espectroscopia. Para a análise espectral estatística das amostras de solo coletadas nas topossequências, utilizou-se o método descrito por Nanni \& Demattê (2006). Assim, em vez de serem utilizadas as 2.150 bandas obtidas com o sensor FieldSpec em laboratório, trabalharam-se com 22 faixas espectrais e 13 alturas. Segundo os autores, essas faixas são específicas e representam todo o espectro em relação às intensidades e feições de absorção.

Para avaliação distintiva da resposta dos dados espectrais e do conjunto de índices topográficos, nas camadas superficiais e subsuperficiais, e individualizados pelas topossequências, realizaram-se análises estatísticas multivariadas de agrupamento (Sneath \& Sokal, 1973). A estratégia de agrupamento utilizada foi a Average Linkage, que permitiu obter agrupamentos sequenciais, aglomerativos, hierárquicos e não superpostos e expressar os resultados pelos gráficos de esquemas hierárquicos ou dendrogramas.

Os dendrogramas, com base tanto nas informações espectrais quanto nas topográficas, foram comparados com a classificação real dos pontos e analisados quanto à sua eficiência em agrupar solos taxonomicamente parecidos e consequentemente determinar limites das unidades de solos em topossequências. Enfim, a obtenção de padrões representativos de classe de solo não é objetivo da análise de agrupamento, já que o que se busca é apenas identificar a similaridade entre os pontos dessas toposequência. O sucesso do processo é alcançado à medida que grupos sejam formados por pontos realmente parecidos e por grupos diversos que tenham pontos que não se parecem entre si e, de preferência, que essa similaridade reúna os grupos de mesma classe de solo.

A validação dos métodos deu-se de forma pontual e espacial. Na primeira, os pontos equidistantes classificados nas topossequências foram tomados como verdadeiros e contrastados com as informações contidas no mapa de solo preexistente e nos dendrogramas, a fim de conferir se a classificação e, ou, os grupos de solos semelhantes indicados por esses métodos correspondiam com a verdade. Já na validação espacial, procurou-se avaliar em que locais os diferentes métodos indicavam mudanças nos limites dos solos e compará-los com as observações reais. Em ambos os casos, representaram-se as topossequências por gráficos, sempre plotando-se sobre esses as informações sugeridas pelos diversos métodos. 


\section{RESULTADOS E DISCUSSÃO}

Os Latossolos Amarelo (LA), Vermelho (LV) e Vermelho-Amarelo (LVA) representam aproximadamente $50 \%$ da área total; entretanto, a classe dos Neossolos Quartzarênicos (RQ) abrange $20 \%$.

A relação espacial dos atributos topográficos estudados (Elevação, Curvatura, Declividade, Índice Topográfico Composto - CTI e Potencial de Densidade de Drenagem - PDD), obtida em razão do mapa de solos simplificado (Figura 1), evidencia, com exceção da Elevação, que não é possível distinguir, de forma clara, as classes de solos. No caso da declividade de uma mesma classe de solo, pode-se encontrar em vários níveis, concordando com Sousa Junior et al. (2008).

Foram definidas topossequências com o comprimento variando de 550 a $4.750 \mathrm{~m}$ e com altitudes variando de 640 a $860 \mathrm{~m}$, abrangendo um (a) Variação da Altitude por Classe de Solo

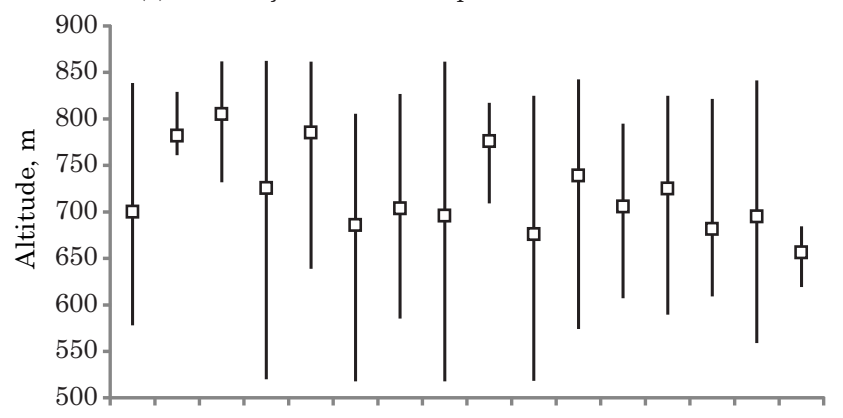

(c) Variação da Declividade por Classe de Solo

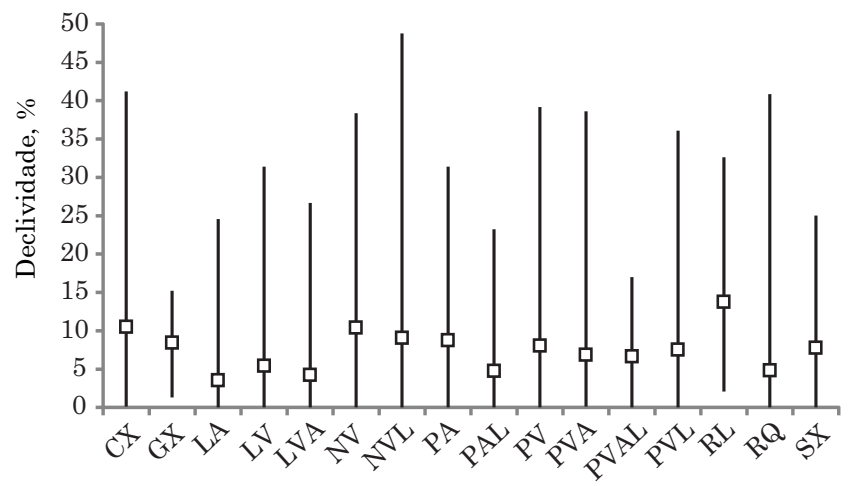

(b) Variação da Curvatura por Classe de Solo

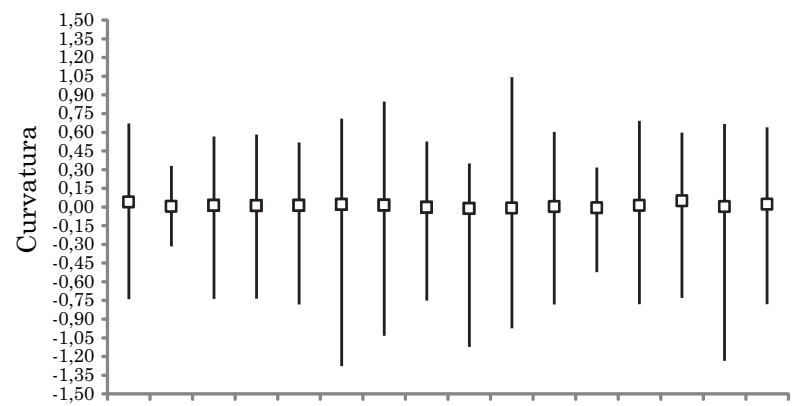

(d) Variação do Índice Topográfico Composta (CTI) por Classe de Solo

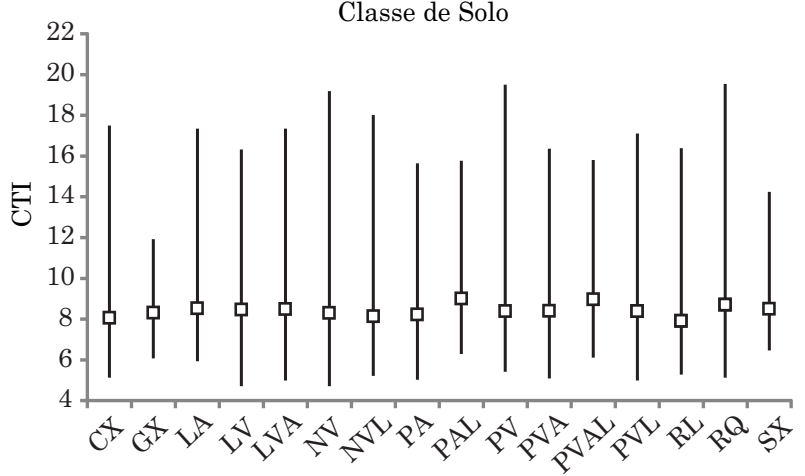

(e) Variação do Potencial de Densidade de Drenagem

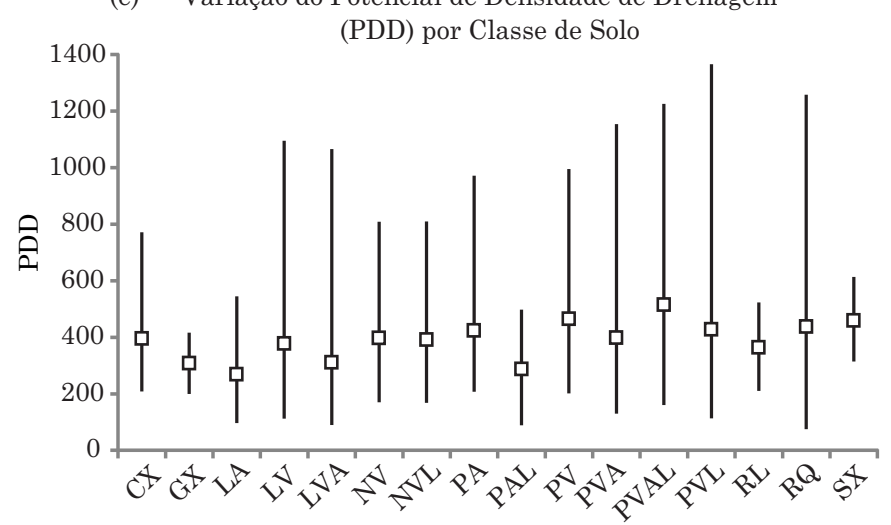

Figura 1. Relação entre os atributos topográficos e as classes de solos estudadas. Nomenclatura de acordo com Embrapa (2006): Cambissolos Háplicos (CX), Gleissolos Háplicos (GX), Latossolos Amarelos (LA), Latossolos Vermelhos (LV), Latossolos Vermelho-Amarelos (LVA), Nitossolos Vermelhos (NV), Nitossolos Vermelhos latossólicos (NVl), Argissolos Amarelos (PA), Argissolos Amarelos latossólicos (PAL), Argissolos Vermelhos (PV), Argissolos Vermelho-Amarelos (PVA), Argissolos Vermelho Amarelos latossólicos (PVAl), Argissolos Vermelhos latossólicos (PVl), Neossolos Litólicos (RL), Neossolos Quartzarênicos (RQ) e Planossolos Háplicos (SX). 
total de 31 unidades de mapeamento. Na maioria das topossequências, verificou-se que os Latossolos ocorrem nas partes superiores, principalmente aqueles com a presença dos solos de matiz amarelo ou vermelhoamarelo (Quadro 2).

Analisando a localização das classes de solo, em relação à elevação (Figura 1a), foi possível perceber que os Planossolos Háplico (SX) são os únicos solos cuja altitude máxima de ocorrência não ultrapassa os 700 m, separando-os dos Gleissolos Háplico (GX), LA e Argissolos Amarelo latossólico (PAL), em que a altitude mínima de ocorrência também não ultrapassa esse valor. Além disso, os LVA ocorreram predominantemente em posições mais elevadas. Observou-se que na classe dos Latossolos que as subordens LA, LVA e LV estão dispostas na paisagem, da parte mais alta para a mais baixa, nessa sequência, com altitude média de 805, 785 e $725 \mathrm{~m}$, respectivamente. Sousa Junior et al. (2008) observaram que nos Latossolos e Argissolos, conforme o matiz vai ficando mais amarelo, há incremento de sua incidência em áreas mais altas e planas nessa região. Entretanto, se o matiz torna-se mais vermelho, há aumento proporcional desses solos nas partes mais baixas do relevo. Esse fato se deve, principalmente, à influência de diferentes materiais de origem no processo de formação desses solos. Nas partes mais altas, há a influência dos arenitos, enquanto nas posições inferiores, do diabásio.

$\mathrm{Na}$ relação entre classes de solos e curvatura do terreno (Figura 1b), observou-se que existe um valor médio próximo a zero; o que faz uma classe se diferenciar da outra é a amplitude entre os valores mínimos e máximos. A classe dos Gleissolos é a que mais tende a ocorrer em intervalos lineares, embora possua baixa representatividade da área total. Os Latossolos estudados (LA, LVA e LV) praticamente não apresentaram diferenças entre si, permanecendo entre uma faixa de -0,8 e 0,6 unidades de curvatura.

Os solos que estão presentes nas áreas mais côncavas são: NV e Nitossolo Vermelho textura muito argilosa (NVl), Argissolo Vermelho textura muito argilosa (PVl) e PV e RQ. Essas áreas estão, em sua maioria, localizadas nos sopés das elevações e servem como locais de deposição de resíduos do material de origem a que pertencem. Na região, destacam-se as cuestas arenítico-basálticas. O limite entre a Depressão Periférica e as Cuestas Basálticas é a frente escarpada, que forma paredões esculpidos em arenito e basalto das Formações Serra Geral, Botucatu e Piramboia. Esse paredão, extremamente íngreme, que

\section{Quadro 2. Caracterização das topossequências definidas na área de estudo}

\begin{tabular}{|c|c|c|c|c|}
\hline Topossequência & Comprimento & $\begin{array}{c}\text { Variação } \\
\text { da altitude }\end{array}$ & $\begin{array}{c}\text { Pontos } \\
\text { de coleta }^{(1)}\end{array}$ & Solo ocorrente ${ }^{(2)}$ \\
\hline & $\longrightarrow$ & 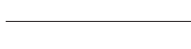 & $\mathrm{n}^{\mathrm{o}}$ & \\
\hline 1 & 3500 & $750-860$ & 11 & LA3+LVA3; PVA3; PV2; \\
\hline 2 & 900 & $690-750$ & 5 & PVAl3; NVf2; CX2; \\
\hline 3 & 550 & $760-780$ & 4 & LA4; PA3; \\
\hline 4 & 4750 & $650-800$ & 15 & LV4, LA3, LV3+PVl2, LVf2, LVf1, NVf1+CX1 \\
\hline 5 & 1300 & $720-790$ & 4 & LV4; PVl2+PV2; NVlf1; NVf2+CX2; \\
\hline 6 & 3200 & $760-850$ & 10 & LV4; LA3+LA3; LVA2; PV2; \\
\hline 7 & 1500 & $740-780$ & 10 & LVA3; LV2; LVf1; \\
\hline 8 & 1300 & $770-810$ & 7 & LA3; LVA3 + PVAl3; PVAl4; \\
\hline 9 & 1800 & $660-790$ & 8 & LVA3; NVf2; \\
\hline 10 & 3300 & $650-770$ & 12 & LVA3+LV3; LA3; LV2; LVf2; NVf2+NVf2; \\
\hline 11 & 2300 & $770-850$ & 8 & LA3+LV3; LVA2; PVA3; NVlf2; \\
\hline 12 & 1500 & $790-850$ & 6 & LA3+LV3; PVA3+PV2; \\
\hline 13 & 2400 & $660-740$ & 14 & LVA4; LV3; LVf2; LV3; RQ5; LVA4; \\
\hline 14 & 2300 & $640-680$ & 10 & LV2; LV4; NVlf2; \\
\hline
\end{tabular}

(1) Amostras de solo coletadas nas profundidades de 0-20 e 80-100 cm. (2) Nomenclatura de acordo com Embrapa (2006): Cambissolos Háplicos textura muito argilosa (CX1); Cambissolos Háplicos textura argilosa (CX2); Latossolos Amarelos textura média argilosa (LA3); Latossolos Amarelos textura média arenosa (LA4); Latossolos Vermelhos textura argilosa (LV2); Latossolos Vermelhos textura média argilosa (LV3); Latossolos Vermelhos textura média arenosa (LV4); Latossolos Vermelho-Amarelos textura argilosa (LVA2); Latossolos Vermelho-Amarelos textura média argilosa (LVA3); Latossolos Vermelho-Amarelos textura média arenosa (LVA4); Latossolos Vermelho férrico textura muito argilosa (LVf1); Latossolos Vermelho férrico textura argilosa (LVf2); Nitossolos Vermelhos férricos textura muito argilosa (NVf1); Nitossolos Vermelhos férricos textura argilosa (NVf2); Nitossolos Vermelhos latossólicos férricos textura muito argilosa (NVlf1); Nitossolos Vermelhos latossólicos férricos textura argilosa (NVlf2); Argissolos Amarelos textura média argilosa (PA3); Argissolos Vermelhos textura argilosa (PV2); Argissolos Vermelho Amarelos textura média argilosa (PVA3); Argissolos Vermelho-Amarelos latossólicos textura média argilosa (PVAl3); Argissolos Vermelho-Amarelos latossólicos textura média arenosa (PVAl4); Argissolos Vermelhos latossólicos textura argilosa (PVl2); Neossolos Quartzarênicos (RQ5). 
em algumas posições do relevo atinge quase a verticalidade total, é representado por exposições de basalto e arenitos Botucatu e Piramboia. Isso explica a presença dos RQ em áreas côncavas, uma vez que essas são depósitos de materiais arenosos. Oliveira \& Prado (1984) realizaram levantamento pedológico semidetalhado da região de São Carlos e verificaram espessos depósitos arenosos, que constituem os cones de dejeção do sopé dessa frente escarpada, desenvolvendo-se ali os RQ.

Analisando as unidades de solos em relação à declividade (Figura 1c), verificou-se que, com exceção dos RQ, os valores médios de declividade, de todas as unidades, estão entre 3 e $11 \%$. Oliveira et al. (1992) relataram que os solos que ocorrem em terrenos íngremes são submetidos ao rejuvenescimento por meio dos processos erosivos naturais, resultando em solos relativamente menos profundos e evoluídos. Neste trabalho, observou-se que NVl, Cambissolo Háplico (CX) e RQ são os solos que aparecem com os valores máximos de declividade, 49, 41 e $40 \%$, respectivamente. Entretanto, Neossolos Litólico (RL), CX e NV são os solos que apresentam as maiores declividades médias com 14,11 e $10 \%$, respectivamente, o que é coerente com Reis et al. (2004), os quais encontraram a maior parte do NV (38,8 \%) distribuído em terrenos ondulados do Paraná. Ippoliti et al. (2005), em um trabalho de delineamento de geoformas e pedopaisagens no município de Viçosa, Minas Gerais, observaram a presença de Cambissolos Háplicos latossólicos (CXL) em declives maiores de $45 \%$. Em contrapartida, Sousa Junior (2005) recomendou fazer uma caracterização local da paisagem que sirva de elemento básico a levantamentos pedológicos.

Os LA, LVA e LV apresentam valores médios de declives muito similares, predominando entre áreas planas e suaves onduladas. Porém, nos LV, observamse declives com até $32 \%$. Isso demonstra a variabilidade espacial que ocorre na correlação entre solo e declive e ressalta a importância de caracterizações regionais. Reis et al. (2004), estudando solos do município de Bandeirantes, Paraná, verificaram a presença desse solo em declive de até $20 \%$. Oliveira et al. (1992) afirmaram que os LVA e LA ocorrem predominantemente em terrenos planos (0 a $3 \%$ ).

Os valores médios do CTI variaram entre 7,9 e 9,0 (Figura 1d), enquanto a amplitude geral variou de 4,7 a 19,5. Esses resultados indicaram boa relação entre o índice topográfico e as áreas de maior saturação hídrica, locais de ocorrência dos valores mais altos, as quais naturalmente encontram-se associadas a canais de drenagem. Esse é o caso dos PV, SX e NV, que tendem a ocorrer em áreas com maior índice de densidade de drenagem, concordando com Demattê \& Demétrio (1998). Resultados similares foram obtidos por Yang et al. (2005), os quais em um trabalho de delineamento de faces da paisagem na costa Australiana, utilizando-se de um MDE de $25 \mathrm{~m}$ de célula, encontraram um valor médio para o CTI de 9,23 com uma variação de 6,74 a 20,79. No Brasil,
Rennó \& Soares (2003) desenvolveram um estudo para estimar a profundidade do lençol freático pelo CTI na bacia hidrográfica do rio Corumbataí, encontrando um valor médio de 9,38. Schuler (1998), trabalhando nessa mesma área, mas utilizando uma grade regular com resolução de $20 \mathrm{~m}$ para representar a topografia, observou índices topográficos ligeiramente menores.

O índice de Potencial de Densidade de Drenagem (PDD) (Figura 1e) é uma mensuração da rede de drenagem ou dissecação do terreno (Dobos, 1998; Dobos et al., 2000). O grau de dissecação é determinado pelo escoamento superficial da água da chuva e pela permeabilidade do solo e extrato rochoso. Os resultados evidenciaram que os maiores valores médios de PDD estão entre os Argissolo Vermelho-Amarelo textura muito argilosa (PVAl), PV e SX, enquanto os menores estão entre os LV, Argissolos Amarelo textura muito argilosa (PAl) e LVA. Ao analisar uma média entre os Latossolos (LA, LV e LVA), Nitossolos (NV e Nitossolo Vermelho textura muito argilosa - NVl) e Argissolos (Argissolo Amarelo - PA, PV, Argissolo VermelhoAmarelo PVA), o PDD apresentou valores de 319, 394, e 429, respectivamente. Isso demonstrou uma diferenciação entre essas classes de solos. À medida que a água da chuva encontra dificuldade para se infiltrar no solo (como nos solos mais argilosos e com presença de horizonte $\mathrm{B}$ textural), aumenta o escoamento superficial e consequentemente há perda de solo por erosão e formação de novos canais de drenagem.

De acordo com o quadro 3, é possível observar algumas tendências entre as correlações. Observouse que as relações entre os atributos topográficos e granulométricos variam para cada topossequência delineada. Tem-se, por exemplo, para a Topossequência 3 , uma correlação entre a elevação e os teores de argila e areia total de -0,99 e 0,99, respectivamente, enquanto na Topossequência 5 , para os mesmos atributos, não houve significância. Esses resultados concordaram com os de Campos et al. (2007), os quais, estudando as relações solo-paisagem em uma topossequência na Região de Pereira Barreto, São Paulo, observaram que os teores de argila do horizonte B tiveram incremento em seus valores das partes mais altas para as mais baixas da paisagem. Graham \& Buol (1990) ressaltaram que esse fato está associado à variação do material de origem e ação do intemperismo. O PDD também apresentou tendência de ter uma correlação positiva com o teor de argila na camada subsuperficial dos solos. Isso se deve ao fato de que com o aumento do teor de argila, principalmente em camadas subsuperficiais, criou-se maior dificuldade para a infiltração da água e assim o escoamento superficial é mais intenso, provocando, consequentemente, maior dissecação hídrica do terreno (Pissarra et al., 2004). Quanto aos índices Curvatura e CTI, não foi observada tendência com os atributos físicos do solo.

Ao realizar uma observação geral entre as 14 topossequências estudadas, verificou-se que o índice 
Quadro 3. Correlação de Pearson entre os atributos físicos dos solos e os índices topográficos (Elevação, Curvatura, Declividade, Índice topográfico composto - CTI, Potencial de Densidade de Drenagem - PDD)

\begin{tabular}{|c|c|c|c|c|c|c|}
\hline & Areia grossa & Areia fina & Areia total & Silte & Argila & Gradiente textural \\
\hline & \multicolumn{6}{|c|}{ Topossequência 1} \\
\hline Elevação & $0,828^{* *}$ & 0,415 & $0,779^{* *}$ & $-0,604^{*}$ & $-0,760^{* *}$ & 0,020 \\
\hline Curvatura & $-0,169$ & 0,035 & $-0,136$ & $-0,094$ & 0,362 & 0,384 \\
\hline Declividade & $-0,274$ & 0,019 & $-0,228$ & 0,185 & 0,214 & 0,096 \\
\hline CTI & 0,192 & $-0,067$ & 0,149 & $-0,176$ & $-0,077$ & 0,141 \\
\hline \multirow[t]{2}{*}{ PDD } & $0,671^{*}$ & $0,818^{* *}$ & $0,724^{*}$ & $-0,731^{*}$ & $-0,511$ & $-0,187$ \\
\hline & \multicolumn{6}{|c|}{ Topossequência 2} \\
\hline Elevação & 0,901 & 0,616 & 0,944 & $-0,907$ & $-0,938$ & $-0,977^{*}$ \\
\hline Curvatura & 0,088 & 0,931 & 0,695 & $-0,819$ & $-0,659$ & $-0,541$ \\
\hline Declividade & $-0,931$ & $-0,397$ & $-0,810$ & 0,615 & 0,838 & 0,904 \\
\hline CTI & 0,585 & 0,498 & 0,681 & $-0,867$ & $-0,632$ & $-0,655$ \\
\hline \multirow[t]{2}{*}{ PDD } & $0,979^{*}$ & 0,275 & 0,753 & $-0,589$ & $-0,776$ & $-0,869$ \\
\hline & \multicolumn{6}{|c|}{ Topossequência 3} \\
\hline Elevação & $0,984^{*}$ & $-0,615$ & $0,988^{*}$ & $-0,914$ & $-0,989^{*}$ & 0,275 \\
\hline Curvatura & $-0,212$ & 0,578 & $-0,123$ & 0,013 & 0,174 & 0,942 \\
\hline Declividade & $-0,784$ & 0,782 & $-0,729$ & 0,512 & 0,811 & $-0,213$ \\
\hline CTI & 0,786 & $-0,778$ & 0,733 & $-0,517$ & $-0,814$ & 0,221 \\
\hline \multirow[t]{2}{*}{ PDD } & 0,153 & 0,573 & 0,288 & $-0,570$ & $-0,135$ & 0,512 \\
\hline & \multicolumn{6}{|c|}{ Topossequência 4} \\
\hline Elevação & $0,847^{*}$ & 0,728 & $0,889^{*}$ & $-0,802$ & $-0,854^{*}$ & $-0,645$ \\
\hline Curvatura & $0,870^{*}$ & 0,741 & $0,911^{*}$ & $-0,913^{*}$ & $-0,726$ & $-0,425$ \\
\hline Declividade & $-0,802$ & $-0,854^{*}$ & $-0,899^{*}$ & 0,775 & $0,925^{* *}$ & 0,555 \\
\hline CTI & 0,090 & 0,017 & 0,073 & $-0,200$ & 0,150 & $-0,675$ \\
\hline \multirow[t]{2}{*}{ PDD } & $-0,724$ & $-0,705$ & $-0,789$ & 0,658 & $0,848^{*}$ & 0,547 \\
\hline & \multicolumn{6}{|c|}{ Topossequência 5} \\
\hline Elevação & $-0,038$ & $0,605^{*}$ & 0,108 & 0,050 & $-0,187$ & $-0,173$ \\
\hline Curvatura & $-0,555^{*}$ & $-0,367$ & $-0,549^{*}$ & $0,702^{* *}$ & 0,424 & $-0,442$ \\
\hline Declividade & $-0,497$ & $-0,801^{* *}$ & $-0,602^{*}$ & 0,407 & $0,664^{* *}$ & 0,018 \\
\hline CTI & $-0,062$ & 0,030 & $-0,045$ & $-0,011$ & 0,073 & 0,347 \\
\hline \multirow[t]{2}{*}{ PDD } & $-0,467$ & $-0,822^{* *}$ & $-0,581^{*}$ & 0,465 & $0,602^{*}$ & $-0,087$ \\
\hline & \multicolumn{6}{|c|}{ Topossequência 6} \\
\hline Elevação & $0,682^{*}$ & $0,703^{*}$ & 0,413 & $-0,210$ & $-0,454$ & $-0,215$ \\
\hline Curvatura & 0,343 & $-0,401$ & 0,180 & $-0,162$ & $-0,178$ & 0,247 \\
\hline Declividade & $-0,089$ & 0,048 & $-0,078$ & 0,199 & 0,041 & 0,030 \\
\hline CTI & $-0,318$ & $-0,328$ & $-0,567$ & 0,315 & 0,615 & 0,061 \\
\hline PDD & $-0,460$ & $-0,136$ & $-0,626$ & $0,655^{*}$ & 0,592 & $-0,289$ \\
\hline
\end{tabular}

$* \mathrm{e}^{* *}$ : significativo a 5 e $1 \%$, respectivamente.

topográfico, que apresentou maior número de correlações significativas com os atributos físicos do solo, foi a elevação do terreno com correlações significativas em 10 topossequências para a areia, seis para silte e sete para argila. O PDD foi o segundo melhor índice a se correlacionar significativamente com os atributos físicos do solo, principalmente com a areia, que, inclusive, foi o melhor atributo a se correlacionar, no geral, com os índices topográficos.

Os índices que obtiveram resultados pouco expressivos em termos de correlação com os atributos físicos do solo foram a declividade e o CTI. Moore et al. (1993) correlacionaram índices topográficos (declividade, aspecto, curvatura, CTI, entre outros) com atributos do solo (profundidade do horizonte $\mathrm{A}$, $\mathrm{pH}$, silte, areia etc.), obtidos na camada superficial e concluíram que existem correlações significativas entre os atributos do terreno e os do solo, destacando que a declividade e o CTI foram os atributos do terreno que mais apresentaram correlação. Entretanto, além de trabalhar com dados da camada superficial, esses autores trabalharam em uma área de estudo pequena, 
sendo apenas uma topossequência com uma variação de declividade de $0-5 \%$, o que difere das topossequências deste trabalho. Gessler et al. (2000) continuaram o trabalho de Moore et al. (1993) e avaliaram, conjuntamente, métodos de análise digital do terreno, observações de campo para o solo e ecossistema, modelagem estatística e interpretações de processos geomorfológicos e pedológicos, tanto para a camada superficial quanto subsuperficial, e concluiram que o CTI e a declividade são mais recomendados para estudos do horizonte A. Isto explica a baixa correlação desses índices com os atributos físicos do solo neste trabalho.

Verifica-se na topossequência (Figura 2) a presença de três grupos de solos: grupo 1 - do ponto 1 ao ponto 6 , envolvendo solos com textura média arenosa (LA4 e LVA4) e média argilosa (LA3 e LVA3); grupo 2 - do ponto 7 ao 9, de textura média argilosa (LV3) e argilosa (LV2 e PV2); e grupo 3, de textura argilosa (PV2). O dendrograma obtido em razão dos dados espectrais permitiu a formação de quatro grupos constituídos pelas similaridades entre as classes de solos, considerando como perda máxima de similaridade a distância euclidiana de 10 . O grupo G1 reuniu os pontos de 1 a 6 , representativos dos solos de textura média, conseguindo inclusive diferenciar os pontos 4 e 5 (textura média arenosa) dos pontos 3 e 6 (textura média argilosa). De fato, a granulometria do solo é um atributo que mais vem se destacando na discriminação de solos pela espectroradiometria, conforme verificado por Demattê (2002). O grupo G2 reuniu os solos de textura argilosa e média argilosa, enquanto o grupo G3, os argilosos (NV2). Já as distâncias euclidianas obtidas as partir dos dados topográficos permitiram elaborar o dendrograma que apresenta a formação de grupos e subgrupos mais heterogêneos que aquele obtido com os dados espectrais, indicando que esse conjunto de atributos não permitiu com clareza a distinção dos solos estudados.

$\mathrm{Na}$ figura 3, indica-se que os Latossolos Amarelos textura média arenosa (LA4) estão dispostos na parte mais alta da topossequência. À medida que a elevação vai diminuindo, os solos vão gradativamente passando para texturas mais argilosas, seguindo a sequência Latossolos Amarelos textura média arenosa (LA4), Argissolos Vermelho-Amarelos textura média argilosa (PVA4) e Nitossolos Vermelhos textura argilosa (NV2). As distâncias euclidianas obtidas com base nos dados espectrais permitiram a formação de três grupos. No grupo G1, incluíram-se os pontos 1 e 2 (Latossolos Amarelos textura média arenosa - LA4); e no G2, o ponto 3 (Argissolo Vermelho-Amarelo textura média argilosa PVA3), considerando para os pontos 1 e 2 uma perda máxima de similaridade de aproximadamente 2 e distinguindo este do ponto 3 (G2) com uma perda máxima de similaridade de aproximadamente 8. Essa análise evidenciou que os dados distinguiram solos de textura média arenosa dos de média argilosa. O grupo G3 consta apenas do ponto 4 (Nitossolos Vermelhos textura argilosa NV2), discriminando esse ponto dos demais.

Assim como aconteceu na topossequência 1, o dendrograma obtido com base nos dados topográficos não foi eficiente para distinguir as classes de solos.

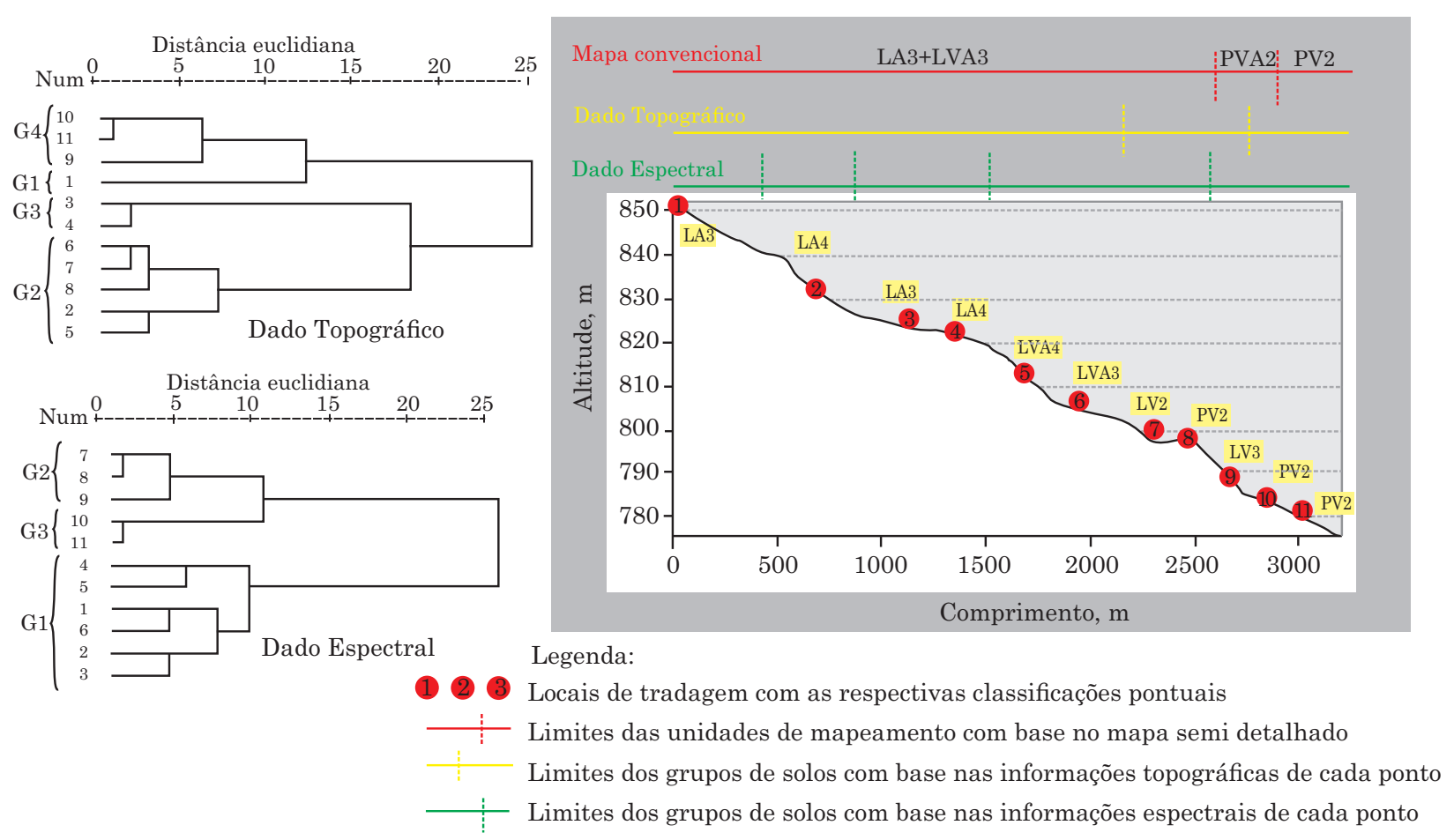

Figura 2. Representação gráfica da Topossequência 1 com as respectivas classificações pedológicas e os dendrogramas das inter-relações dos 11 pontos referentes aos atributos topográficos e espectrais. 
Entretanto, o gráfico (Figura 2) apresenta que solos de textura argilosa e arenosa ocorrem em paisagens similares.

Na figura 4, está ilustrada uma topossequência, onde a disposição dos solos, da parte mais alta para a mais baixa, é composta de Latossolos Amarelos textura média argilosa - LA3 (pontos 1 e 3), Latossolos Vermelho-Amarelos textura média argilosa - LVA3 (pontos 3 e 4), Argissolos Vermelhos textura média argilosa - PV3 (ponto 5) e Argissolos Vermelhos textura argilosa - PV2 (ponto 6). O dendrograma com base nos dados espectrais distinguiu três grupos de solos (G1, G2 e G3), onde o grupo G1 reuniu os Latossolos; e os grupos G2 e G3 agregaram os Argissolos Vermelhos textura média argilosa e argilosa - PV3 e PV2, respectivamente. Assim, além de separar os solos quanto à classe textural, ainda foi possível separar os Latossolos dos Argissolos.

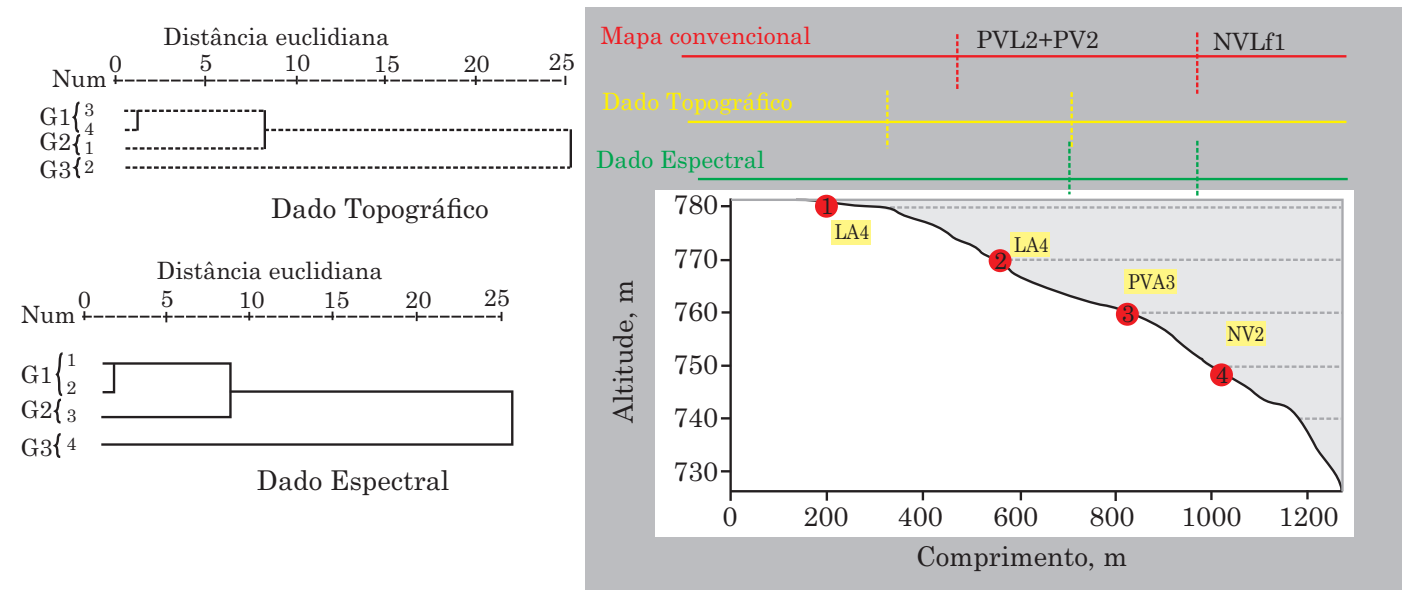
(1) 23 Locais de tradagem com as respectivas classificações pontuais
\begin{tabular}{l} 
L Limites das unidades de mapeamento com base no mapa semi detalhado \\
\hline
\end{tabular}
- Limites dos grupos de solos com base nas informações espectrais de cada ponto

Figura 3. Representação gráfica da Topossequência 5 com as respectivas classificações pedológicas e os dendrogramas das inter-relações dos quatro pontos referentes aos atributos topográficos e espectrais.

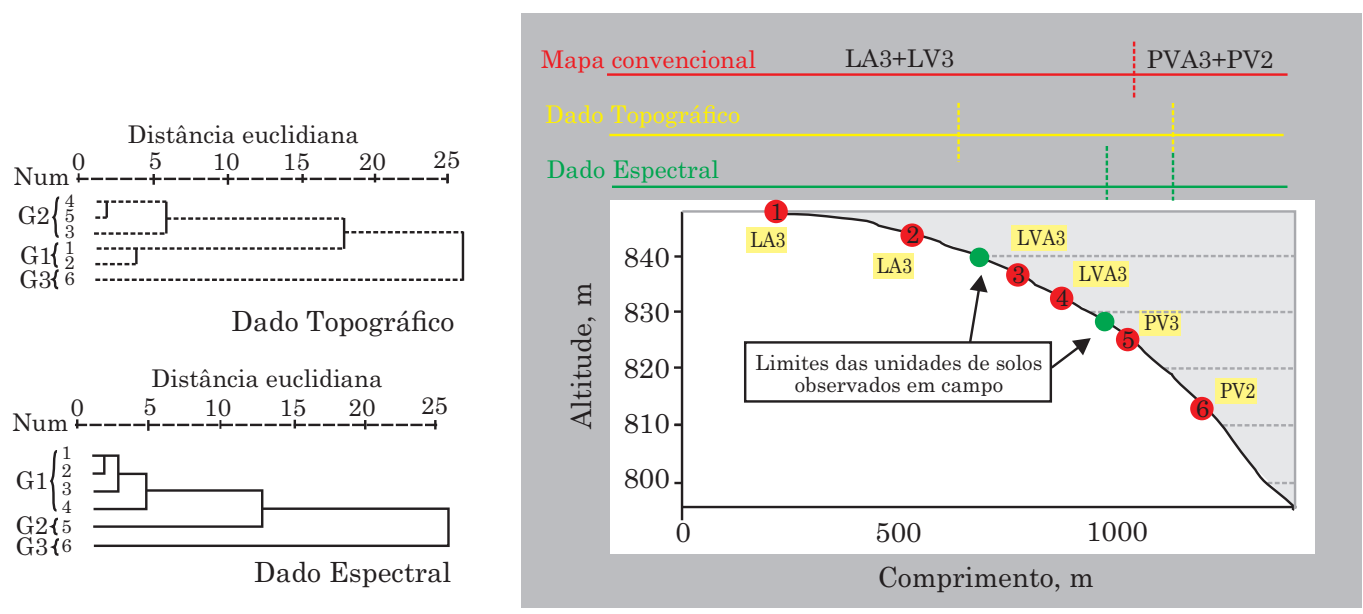

Legenda:

(1) 23 Locais de tradagem com as respectivas classificações pontuais

- Limites das unidades de mapeamento com base no mapa semi detalhado

Limites dos grupos de solos com base nas informações topográficas de cada ponto

_- Limites dos grupos de solos com base nas informações espectrais de cada ponto

Figura 4. Representação gráfica da Topossequência 12 com as respectivas classificações pedológicas e os dendrogramas das inter-relações dos seis pontos referentes aos atributos topográficos e espectrais. 
Observando-se o dendrograma à esquerda da (Figura 4) e com base nas informações topográficas, percebeu-se que para essa topossequência foi possível distinguir os solos quanto à localização no relevo em três grupos distintos: G1 (pontos 1 e 2); G2 (pontos 3, 4 e 5); e G3 (ponto 6). Ao contrário do dendrograma com base nos dados espectrais que separam os Latossolos dos Argissolos, esse separou os Latossolos Amarelos textura média argilosa (LA3) dos Latossolos Vermelho-Amarelos textura média argilosa (LVA3) e juntou, a esse último, os Argissolos Vermelhos textura média argilosa (PV3). Os Argissolos Vermelhos textura argilosa (PV2) ficaram totalmente separados desses grupos. Assim, associando este resultado com observações realizadas em campo (pontos verdes da figura 4), verificou-se que foi possível compartimentar a paisagem em três ambientes principais e associar a cada um desses um grupo de solos.

\section{CONCLUSÕES}

1. O comportamento espacial dos solos em relação aos índices topográficos estudados foi variável. Em relevos com diferentes características pode ocorrer o mesmo solo. Entretanto, utilizando-se do índice de elevação do terreno é possível distinguir os Planossolos Háplicos dos Gleissolos Háplicos (SX), Latossolos Amarelos (LA) e Argissolos Amarelos latossólicos (PAL).

2. A Elevação foi o índice topográfico que melhor se correlacionou com os atributos físicos dos solos, tanto para os obtidos de forma pontual como para os descritos nas topossequências e em análises em subsuperfície.

3. Os índices topográficos CTI e Declividade não foram indicados para correlação com os atributos físicos do solo obtidos em subsuperfície.

4. A análise de agrupamento hierárquico com cluster evidenciou-se eficiente na discriminação das classes de solos numa topossequência, quando utilizados parâmetros espectrais do solo.

\section{AGRADECIMENTO}

Os autores agradecem o grupo de pesquisa GeoCiS (Geotecnologia em Ciência do Solo), http:// esalqgeocis.wix.com/geocis.

\section{LITERATURA CITADA}

BEN-DOR, E.; PATKIN, K.; BANIN, A. \& KARNIELI, A. Mapping of several soil properties using DAIS-7915 hyperspectral scanner data - A case study over clayey soils in Israel. Inter. J. Rem. Sens., 23:1043-1062, 2002.
CAMARGO, A.O.; MONIZ, A.C. \& VALADARES, J.M. Métodos de análise química, mineralógica e física de solos do IAC. Campinas, Instituto Agronômico de Campinas, 1986. 94p. (Boletim Técnico, 106)

CAMARGO, M.N.; KLANT, E. \& KAUFFMAN, J.H. Classificação de solos usada em levantamentos pedológicos no Brasil. B. Inf. SBCS, 12:11-13, 1987.

CAMPOS, M.C. C.; MARQUES JÚNIOR, J. \& PEREIRA, G.T. Relações solo-paisagem em uma litossequência arenitobasalto na região de Pereira Barreto, SP. R. Bras. Ci. Solo, 31:519-529, 2007.

CAMPOS, R.C.; DEMATTÊ, J.A.M. \& QUARTAROLLI, C.F. Determinação indireta do teor de hematita no solo a partir de dados de colorimetria e radiometria. Pesq. Agropec. Bras., 38:521-528, 2003.

DEMATTÊ, J.A.M. \& DEMÉTRIO, V.A. Caracterização de solos por padrões de drenagem e sua relação com índices de intemperismo. Pesq. Agropec. Bras., 33:87-95, 1998.

DEMATTÊ, J.A.M. Characterization and discrimination of soils by their reflected electromagnetic energy. Pesq. Agropec. Bras., 37:1445-1458, 2002.

DOBOS, E. Quantitave analysis and evaluation of AVHRR and terrain data for small scale soil pattern recognition. West Lafayette, Purdue University, 1998. (Tese de Doutorado)

DOBOS, E.; MICHELI, E.; BAUMGARDNER, M.F.; BIEHL, L. \& HELT, T. Use of combined digital elevation model and satellite radiometric data for regional soil mapping. Geoderma, 97:367-391, 2000.

EMPRESA BRASILEIRA DE PESQUISA AGROPECUÁRIA EMBRAPA. Sistema brasileiro de classificação de solos. 2.ed. Rio de Janeiro, Embrapa Solos, 2006. 306p.

ENVIRONMENTAL SYSTEMS RESEARCH INSTITUTE ESRI. ArcGis 9.2. Redlands, 2006. 3 CD-ROM

GESSLER, P.E.; CHADWICK, O.A.; CHAMRAN, F.; ALTHOUSE, L. \& HOLMES, K. Terrain attributes. Soil Sci. Soc. Am. J., 64:2046-2056, 2000.

GESSLER, P.E.; MOORE, I.D.; McKENZIE, N.J. \& RYAN, P.J. Soil-landscape modeling and spatial prediction of soil attributes Integrating GIS and environmental modeling. Inter. J. Geogr. Inf. Syst., 9:421-432, 1995. (Special Issue)

GIRGIN, B.N. \& FRAZIER, B.E. Landscape position and surface curvature effects on soils developed in the Palouse area, WA. Pullman, Washington State University, Department of Crop and Soil Sciences, 1996.

GOODMAN, A. Trend surface analysis in the comparison of spatial distributions of hillslope parameters. 1999. (Tese de Doutorado) Disponível em: <http://www.deakin.edu.au/ agoodman/masters/index.html>. Acesso em: 15 mar. 2007.

GRAHAM, R.C. \& BUOL, W. Soil-geomorphic relations on the Blue Ridge Front: II. Soil characteristics and pedogenesis. Soil Sci. Soc. Am. J., 54:1367-1377, 1990.

HUTCHINSON, M.F. Development of a continent-wide DEM with applications to terrain and climate analysis. In: GOODCHILD, M.F., ed. Environmental modeling with GIS. New York, Oxford University Press, 1993. p.392-399. 
IPPOLITI, R.G.A.; COSTA, L.M.; SCHAEFER, C.E.G.R.; FERNANDES FILHO, E.I. \& GAGGERO, M.R. Digital terrain analysis: Tool for pedoform identification in the "Mar de Morros" (MG). R. Bras. Ci. Solo, 29:269-276, 2005.

McKENZIE, N.J.; GESSLER, P.E.; RYAN, P.F. \& O'CONNELL, D.A. The role of terrain analysis in soil mapping. In: WILSON, J.P. \& GALLANT, J.C., eds. Terrain analysis: Principles and applications. New York, John Wiley \& Sons, 2000. p.245-265.

MOORE, I.D.; GESSLER, P.E. \& NIELSON, G.A. Soil attribute prediction using terrain analysis. Soil Sci. Soc. Am. J., 57:443-452, 1993.

MOORE, I.D.; GRAYSON, R.B. \& LADSON, A.R. Digital terrain modeling: A review of hydrological, geomorphological and biological applications. Hydrol. Proc., 5:3-30, 1991.

NANNI, M.R. \& DEMATTÊ, J.A.M. Spectral methodology in comparison to traditional soil analysis. Soil. Sci. Soc. Am. J., 70:393-407, 2006.

OLIVEIRA, J.B.; JACOMINE, P.K.T. \& CAMARGO, M.N. Classes gerais de solos do Brasil: guia auxiliar para seu reconhecimento. 2.ed. Jaboticabal, FUNEP, 1992. 201p.

OLIVEIRA, J.B. \& PRADO, H. Levantamento pedológico semidetalhado do Estado de São Paulo: Quadrícula de São Carlos. Memorial descritivo. Campinas, Instituto Agronômico de Campinas, 1984. 118p.

PACHEPSKY, Y.A.; TIMLIN, D.J. \& RAWLS, W.J. Soil water retention as related to topographic variables. Soil. Sci. Soc. Am. J., 65:1787-1795, 2001.

PISSARRA, T.C.T.; POLITANO, W. \& FERRAUDO, A.S. Avaliação de características morfométricas na relação solo-superfície da bacia hidrográfica do Córrego Rico, Jaboticabal, SP. R. Bras. Ci. Solo, 28:297-305, 2004. Disponível em: <http://www.scielo.br/ scielo.php?script=sci_arttext\&pid=S0100 06832004000200008\&lng $=e n \& n r m=i s o>$. Acesso em: 23 out. 2005 .

REIS, T.E.S.; BARROS, O.N.F. \& REIS, L.C. Utilização de sistema de informações geográficas para obtenção das cartas de solo e de declividade do município de Bandeirantes-PR. Geografia, 13:1-17, 2004.

RENNÓ, C.D. \& SOARES, J.V. Uso do índice topográfico como estimador da profundidade do lençol freático. In: SIMPÓSIO BRASILEIRO DE SENSORIAMENTO REMOTO, 11., Belo Horizonte, 2003. Anais... São José dos Campos, INPE, 2003. p.2579-2588. CD-ROM
SAVITZKY, A. \& GOLAY, M.J. Soothing and differentiation of data by simplified least squares procedures. Anal. Chem., 36:1627-1639, 1964.

SCHULER, A.E. Aplicação do TOPMODEL em uma bacia de mesoescala localizada na cabeceira do rio Corumbataí. São Carlos, Universidade de São Paulo, 1998. 190p. (Dissertação de Mestrado)

SNEATH, P.H. \& SOKAL, R.R. Numerical taxonomy: The principles and practice of numerical classification. San Francisco, W.H. Freeman, 1973. 573p.

SOUSA JUNIOR, J.G.A. Sensoriamento remoto e sistema de informações geográficas na caracterização de solos e quantificação de seus atributos. Piracicaba, Escola Superior de Agricultura Luiz de Queiroz, 2005. 141p. (Dissertação de Mestrado)

SOUSA JUNIOR, J.G.A.; DEMATTE, J.A.M. \& GENU, A.M Comportamento espectral dos solos na paisagem a partir de dados coletados por sensores terrestre e orbital. R. Bras. Ci. Solo, 32:27-738, 2008.

VISCARRA-ROSSEL， R.A.; WALVOORT, D.J.J.; McBRATNEY, A.B.; JANIK, L.J. \& SKJEMSTAD, J.O. Visible, near infrared, mid-infrared or combined diffuse reflectance spectroscopy for simultaneous assessment of various soil properties. Geoderma, 131:59-75, 2006b.

VISCARRA-ROSSEL, R.A.; McGLYNN, R.N. \& McBRATNEY, A.B. Determining the composition of mineral-organic mixes using UV-VIS-NIR diffuse reflectance spectroscopy. Geoderma, 137:70-82, 2006a.

YANG, X., CHAPMAN, G.A.; YOUNG, M.A. \& GRAY, J.M. Using compound topographic index to delineate soil facets from digital elevation models for comprehensive coastal assessment. In: MODSIM 2005 INTERNATIONAL CONGRESS ON MODELLING AND SIMULATION, 2005, Victoria. Proceedings... Victoria, Modeling and Simulation Society of Australia and New Zealand, 2005. p.1511-1517.

ZHU, A.X.; HUDSON, B.; BURT, J.; LUBICH, K. \& SIMONSON, D. Soil mapping using GIS, expert knowledge, and fuzzy logic. Soil Sci. Soc. Am. J., 65:1463$1472,2001$.

ZHU, J. \& JOSSMAN, P. Application of design patterns for object-oriented modeling of power systems. IEEE Trans. Power Syst., 14:532-537, 1999.

ZIADAT, F.M. Analyzing digital terrain attributes to predict soil attributes for a relatively large area. Soil Sci. Soc. Am. J., 69:1590-1599, 2005. 